\title{
Dielectric properties of piezoelectric 3-0 composites of lithium ferrite/barium titanate
}

\author{
P SARAH* and S V SURYANARAYANA ${ }^{\dagger}$ \\ CVR College of Engineering, Vastunagar, Mangalpalli (V), R.R. District 501 510, India \\ Department of Physics, Osmania University, Hyderabad 500 007, India
}

MS received 23 January 2003; revised 15 September 2003

\begin{abstract}
Piezoelectric 3-0 composite ceramics are prepared from a mixture of barium titanate and lithium ferrite phase constituents. Dielectric properties of composites are affected by a number of parameters that include electrical properties, size, shape and amount of constituent phases. The frequency dependent measurements can provide additional insight into mechanisms controlling electrical response. Frequency dependence of dielectric constant plots of lithium ferrite/barium titanate composites will be given and the relevance of trends seen in them will be discussed. Connectivity in composites developed is studied.
\end{abstract}

Keywords. Composites; dielectric constant; connectivity; barium titanate; lithium ferrite.

\section{Introduction}

3-0 composites are analogous to the fabrication of a brick wall, wherein one phase acts as bricks and the second phase acts as mortar. The designation 3-0 refers to the connectivity of the elements in each phase, i.e. the first phase exhibits three-dimensional connectivity while the entrapped phase exhibits no inter particle connectivity. Sol-gel derived 3-0 composite ceramics exhibit several potential advantages and are developed for application in electronic components (Barrow et al 1997). In the present work, piezoelectric 3-0 composites with lithium ferrite $\left(\mathrm{LiFe}_{5} \mathrm{O}_{8}\right)$ and barium titanate $\left(\mathrm{BaTiO}_{3}\right)$ as the constituent phases, are synthesized.

Barium titanate is a ferroelectric with widespread applications as capacitor material because of its high dielectric constant. Dielectric properties are found to be dependent on the grain size (Kneripkamp and Heywang 1954; Hemings and Rosenstein 1984; Bell 1994). Barium titanate with a large room temperature dielectric constant is mainly used in multilayer capacitor applications, thus the grain size control is very important. Arlt et al (1985) studied domain structures in barium titanate ceramics and showed that room temperature dielectric constant reached a peak value at a critical grain size of $0.7 \mu \mathrm{m}$. Bussem and coworkers (1966) proposed that the internal stresses in fine-grained barium titanate must be much greater than that in coarsegrained barium titanate, thus leading to higher dielectric constant.

Lithium ferrite is found to lose appreciable amount of lithium when heated above $1000^{\circ} \mathrm{C}$ (Ridgley et al 1970).

\footnotetext{
*Author for correspondence
}

Sol-gel process provides a low temperature route for preparing ceramic material with excellent homogeneity, small grain sizes, low impurity levels and customizable physical features.

There is enormous literature (Herbert 1985; Moulson and Herbert 1990; Nowotny 1992) on properties of $\mathrm{BaTiO}_{3}$ and effect of dopants on the properties. A variety of techniques have been used for making piezocomposites (Klicker et al 1981; Savakus et al 1982). In the present work it is proposed to study dielectric constant of composites with two phases, viz. lithium ferrite and barium titanate. Solgel method is used for synthesis to attain smaller grain size, homogeneity and better connectivity.

Modeling of the electrical properties of composites is desirable not only in being able to predict the electrical properties, but may also be used to predict the mechanical properties. Many mixing models exist which allow for property prediction. These models include the following:

(i) Dielectric constant of composites is contributed from both the phases present. It is illustrated as a simple sum property (Newnham 1986) where the $x-y$ effect of the composite is the result of the combination of the same $x-y$ effect of the constituent phases.

$$
\varepsilon=V_{1} \varepsilon_{1}+V_{2} \varepsilon_{2}+.
$$

(ii) Jayasundere and Smith (1993) have presented an expression for the dielectric constant of 3-0 connectivity composites

$$
F(\varepsilon)=\frac{V_{1}\left(\varepsilon_{1}-\varepsilon\right)}{\left(\varepsilon_{1}+2 \varepsilon\right)}+\frac{V_{2}\left(\varepsilon_{2}-\varepsilon\right)}{\left(\varepsilon_{2}+2 \varepsilon\right)},
$$

where $V_{1}$ and $V_{2}$ are the volume fractions, $\varepsilon_{1}$ and $\varepsilon_{2}$ the dielectric constants of the two constituent phases and $\varepsilon$ 
the dielectric constant of the composite. For 3-0 connectivity, the function $F(\varepsilon)$ is predicted to be zero.

\section{Experimental}

Lithium ferrite was prepared by sol-gel method. Lithium oxide and iron oxide were taken in the form of carbonates and nitrates, respectively. Lithium carbonate was dissolved in $\mathrm{HNO}_{3}$ to obtain lithium nitrate. Ferric nitrate was dissolved in water. Both these nitrate solutions were mixed and $1 \mathrm{~g}$ molar quantity of citric acid was added to form a chelate. Ethylene glycol was added and this was heated at $800^{\circ} \mathrm{C}$ to form a gel. This gel was decomposed to a fine powder of lithium ferrite. The formation of single-phase lithium ferrite was identified by XRD. This powder was thoroughly mixed with commercially acquired AR grade barium titanate for the formation of diphasic composites of lithium ferrite/barium titanate. Composites were fabricated with 10-60 vol.\% of barium titanate. These composites were pressed into circular discs and finally sintered at $1000^{\circ} \mathrm{C}$. XRD studies confirmed the presence of both the phases. Measurements concerning dielectric properties as a function of frequency were made using model HP 4192A impedance analyser. Measurements were made in the frequency range $500 \mathrm{~Hz}-10 \mathrm{MHz}$ at room temperature.

\section{Results and discussion}

Dielectric constant values as a function of frequency at room temperature are shown in figure 1. The dielectric constant of lithium ferrite was found to be 140 at $500 \mathrm{~Hz}$. This value was found to fall rapidly at low frequencies and become more or less constant at frequencies above $10^{5} \mathrm{~Hz}$. Lithium ferrite shows low frequency dispersion of dielectric constant, which is attributed to the pores in the sample. The dielectric constant of barium titanate was

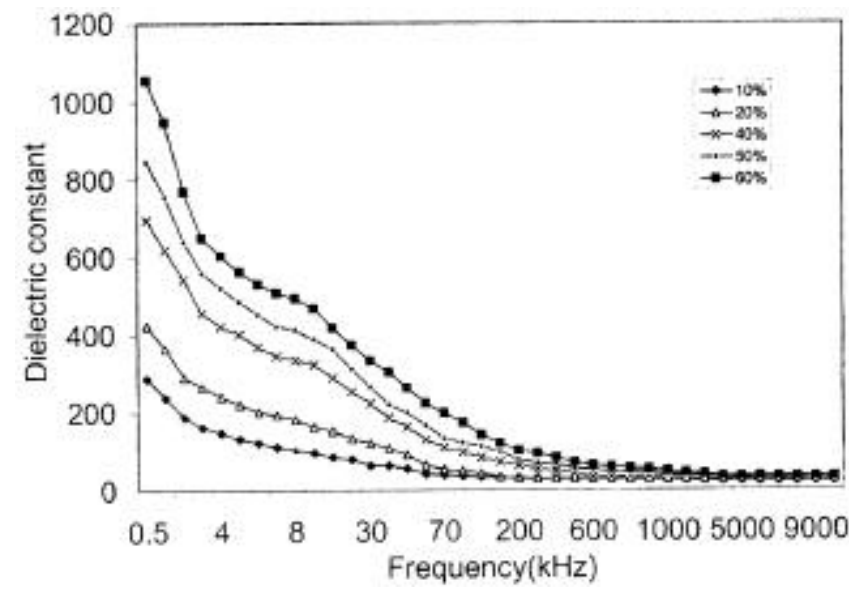

Figure 1. Variation of dielectric constant as a function of frequency for lithium ferrite and composites. found to be 1500 at $500 \mathrm{~Hz}$ and was found to fall rapidly with increasing frequency. There is an increase in dielectric constant as the vol.\% of barium titanate increases.

Dielectric constant is a simple sum property. The results comparing the experimentally observed values and those evaluated using (1) are shown in figure 2. The agreement is good at lower concentrations of barium titanate and there is a deviation at higher concentrations. Equation (1) does not take care of possible contributions of grain boundaries and pores to the dielectric constant. Thus it may be concluded that the difference between the theoretical and experimental values is due to the grain boundaries and pores.

The densities of the composites are given in table 1. It is observed that the density decreases with increasing content of barium titanate indicating the presence of pores in composites with higher content of barium titanate. Thus the difference in the theoretical and experimental values at higher concentrations of barium titanate is attributed to the grain boundaries and the pores present in these composites.

Equation (2) was used to compare the experimental results obtained. The calculation was done and the results are given in table 2. Connectivity of the composites plays a significant role in determining the use and final properties. It was predicted that for 3-0 connectivity, the function $F(\varepsilon)$ should be zero (Jayasundere and Smith 1993).

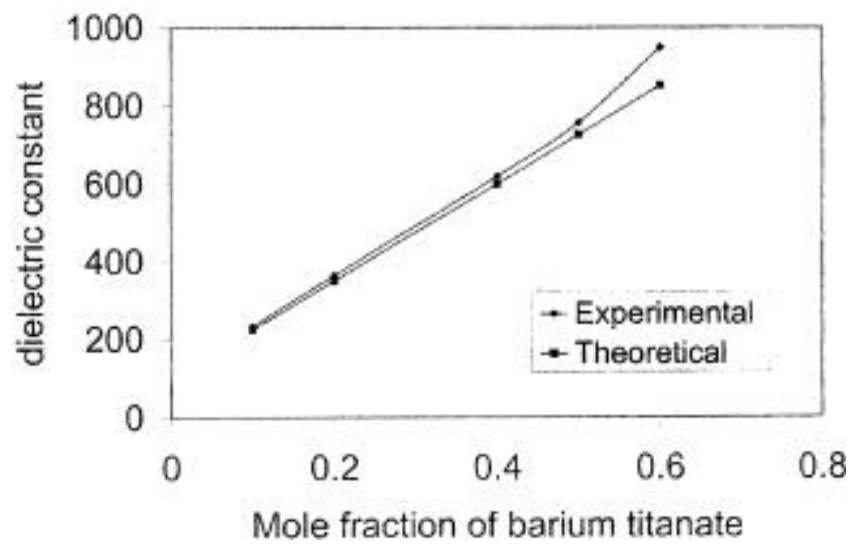

Figure 2. Comparison of experimental and theoretical values of dielectric constant at $1 \mathrm{kHz}$ for different contents of barium titanate.

Table 1. Density of diphasic composites.

\begin{tabular}{lc}
\hline $\begin{array}{l}\text { Sample \% of } \\
\text { barium titanate }\end{array}$ & Density \\
\hline $10 \%$ & 4.72 \\
$20 \%$ & 4.70 \\
$40 \%$ & 4.70 \\
$50 \%$ & 4.67 \\
$60 \%$ & 4.67 \\
\hline
\end{tabular}


Table 2. Values of $F(\varepsilon)$ for diphasic composites.

\begin{tabular}{ll}
\hline $\begin{array}{l}\text { Sample \% of } \\
\text { barium titanate }\end{array}$ & $F(\varepsilon)$ \\
\hline $10 \%$ & -0.15 \\
$20 \%$ & -0.15 \\
$40 \%$ & -0.091 \\
$50 \%$ & -0.092 \\
$60 \%$ & -0.097 \\
\hline
\end{tabular}

In these composites, the functional value was found to deviate slightly from zero, though the deviation was less for samples with higher content of barium titanate with a minimum value at $40 \%$ of barium titanate. Thus the composite with $40 \%$ barium titanate has better 3-0 connectivity.

\section{Conclusions}

Piezoelectric 3-0 connectivity composites were fabricated with $10-60$ vol.\% of barium titanate. The values of dielectric constant varied between 140 and 1500 depending upon the content of $\mathrm{BaTiO}_{3}$. The value of dielectric constant increased with increasing content of $\mathrm{BaTiO}_{3}$. Experimental values agreed well with theoretical values in composites with lower content of $\mathrm{BaTiO}_{3}$. The deviation from theoretical values for higher content of barium titanate is attributed to their lower densities, i.e. the presence of pores. The composites showed near 3-0 connec- tivity. The composite with $40 \%$ barium titanate showed better 3-0 connectivity.

\section{Acknowledgement}

One of the authors (PS) thanks the management of CVR College of Engineering, Mangalpalli, for their encouragement.

\section{References}

Arlt G, Hennings D and deWith G 1985 J. Appl. Phys. 584

Barrow D A, Petroff T E, Tandon R P and Sayer M $1997 \mathrm{~J}$. Appl. Phys. 81876

Bell A J 1994 Proc. ins. symp. appl. ferroelectrics

Bussem W R, Gross L E and Goswami A K 1966 J. Am. Ceram. Soc. 752927

Hemings D and Rosenstein G 1984 J. Am. Ceram. Soc. 67249

Herbert J M 1985 Ceramic dielectric and capacitors (New York: Gordon and Breach Science)

Jayasundere N and Smith B V 1993 J. Appl. Phys. 732462

Klicker K A, Biggers J V and Newnham R E 1981 J. Am. Ceram. Soc. 645

Kneripkamp H and Heywang W 1954 Z. Angew. Phys. 6385

Moulson A J and Herbert J M 1990 Electroceramics: Materials properties and applications (London: Chapman and Hall)

Newnham R E 1986 Am. Rev. Mater. Sci. 1647

Nowotny J 1992 Electronic ceramic materials (Brookfield, V.T.: Trans. Tech.)

Ridgley D H, Lessoff M and Childres J D $1970 \mathrm{~J}$. Am. Ceram. Soc. $\mathbf{5 3} 304$

Savakus H P, Klicker K A and Newnham R E 1982 Mater. Res. Bull. 16677 